\title{
Public opinion on age stereotypes during the COVID-19 pandemic
}

\author{
Gabriella Sandstig \\ Department of Journalism, Media and Communication, University of Gothenburg \\ PO Box 710, 40530 Gothenburg Sweden
}

\begin{abstract}
The news media can both mirror age stereotypes held by the public, as well as contribute to constructing or amplifying them. The first risk group identified in the pandemic was older adults. They are generally not so visible in the media, but during the pandemic, they were in focus. This study analyses to what extent the public agrees with age stereotypes during the COVID-19 pandemic and what characterizes the groups that hold them. Survey data from $04 / 14 / 20-06 / 28 / 20$ on a national sample (6000) of the population of Sweden is used. The results, contrary to the expectation that stereotypes of older adults should dominate the public opinion, rather the stereotype of younger people not distancing themselves enough is the most common. However, the corresponding stereotype of older adults not doing the same is the second most common. In a non-crises situation, the most common stereotype of older adults is that they have poor cognitive abilities. However, this stereotype is rare during the pandemic. The characteristic of the group that agree with the stereotypes are that they are young rather than old. There are also differences by gender, education and residential area, but they vary depending on the specific age stereotype in question.
\end{abstract}

Keywords - Age stereotypes, COVID-19, Crisis, Pandemic, Public opinion

SUGGESTED CITATION: Sandstig, G. (2021). Public opinion on age stereotypes during the COVID-19 pandemic. Proceedings of the International Crisis and Risk Communication Conference, Volume 4 (pp. 29-32). Orlando Fl: Nicholson School of Communication and Media. https://doi.org/10.30658/icrcc.2021.07

\section{INTRODUCTION}

Globally, as well as in Sweden, the aging population is growing faster than all other age groups [1]. An assumption is therefore that the importance of meeting the needs of older adults, where effective risk communication is one, will increase. In the pandemic, older adults where the first risk group identified. We know that news media can both mirror age stereotypes held by the public as well as contribute to constructing and possibly amplifying them. According to the Global AgeWatch Index, Sweden is one of the world's best countries to age in. At the same time, the World Values Survey, which examines people's values in more than 100 countries, shows that Sweden is one of the countries where older adults is perceived to have the weakest social position in society. So in this study the flashlight is directed towards the Swedish public, and the aim of the study is to analyse to what extent the public agrees or disagrees with statements of age stereotypes during the COVID-19 pandemic and what characterizes the groups that agree or disagree.

In the literary review that follows, a short summary of the results of previous research on age stereotypes in the media, and the universally shared public perception of age stereotypes in different countries is made. The design of the cross-sectional survey is then described in the method section. In the result section that follows, the three main results are described and compared with the results of previous research. The proceeding ends with a discussion of how to understand the unexpected results, and a conclusion where the relevance for risk and crisis communication is elaborated.

\section{LITERAURE REVIEW}

Age stereotypes is here defined as images of aging and older adults and people's conscious and unconscious perceptions of the same [2] as well as associating particular characteristics with a specific age group without paying attention to the diversity or heterogeneity within this group [3]. When it comes to age stereotypes in the media we know that older adults often are portrayed in a stereotypical and generalized way $[4,5]$ and that negative age stereotypes are more common than positive ones [4]. The negative age stereotypes in the media portray older adults as kind but incompetent [4], fragile, senile, unarticulated, depressed, lonely and neglected [6] or as weak, unattractive and useless [7]. We also know that in contrast to stereotypes due to ethnicity, skin colour and country of origin, age stereotypes lack associations with elements such as not liking or not tolerating older adults [4]. We also know that there are universally shared perceptions of age 
stereotypes independent of country or culture $[4,5]$. One of them is that that older adults (are kind, but) have poor cognitive skills [8]. However there are studies that shows a tendency towards that the public in collectivistic cultures have a more negative attitudes toward older adults, than in individualistic ones [9].

\section{METHOD}

Cross Sectional Survey data from the SOM-Institute, University of Gothenburg, Sweden, in field between 04/14/20$06 / 28 / 20$ on a national sample $(6000)$ of the population of Sweden, age 16-85 years, was used. The survey had the specific focus to capture the reactions, opinions and behaviours of the population in the beginning and in the midst of the corona pandemic. The questionnaire contained 16 pages of questions. 2549 respondents answered, which corresponds to a net response rate of 44 percent. Analyses show that the demographic representativeness in the response group is relatively good. Representativeness regarding gender and age and country of birth, on the other hand, is somewhat skewed. Men, younger people and people born in non-European countries belong to the groups that are less represented among the respondents.

The public opinion of age stereotypes was operationalized through the question 'To what extent do you agree with the following statements?', followed by three statements in the following order: 'Individuals above the age of 70 do not limit their contacts with other people sufficiently due to the coronavirus'; 'Individuals below the age of 30 do not limit their contact with other people sufficiently due to the coronavirus' and 'Individuals above the age of 70 lack the knowledge of how to protect themselves from the coronavirus'. The options to answer where in the following order 'Agree completely'; 'Partially Agree'; 'Hardly Agree'; 'Do not agree at all' and 'No opinion'.

The third statement was based on the universally shared perception that older adults would have poorer cognitive abilities than other age groups and customized to suit the corona pandemic. The first and second statement was not specifically based on previous research, but rather the nature of the early protective recommendations during the corona pandemic to avoid traveling and to keep a social distance, combined with news reporting in Sweden of older adults not restricting their spring travels to other countries. Since research on age stereotypes, even though biased, is not only about stereotypical notions about individuals who are older, but also about individuals who are younger, the corresponding second statement, about insufficient social distancing among people younger than 30 years, was formulated.

The question was funded by AgeCap-Centre for Aging and Health, University of Gothenburg, Sweden. IBM SPSS Statistics 27 was used for the statistical analysis.

\section{RESULTS}

RESULTS 1

Based on the results of previous research were a common age stereotype in the media [4, 5], as well as universally indifferent of country [8], in a non-crises situation, is that older adults have poor cognitive skills, the expectations was that the public opinion on age stereotypes of older adults poorer cognitive skills would be the most agreed upon. However the result is that the statement on the age stereotype of individuals over the age of 70 years having poorer cognitive skills is the least agreed upon by the public during the COVID-19 pandemic. Nearly a quarter of the public agree completely or partially with this age stereotype, but a higher share, almost two thirds of the public, do not agree at all or hardly with this age stereotype. Thus the age stereotype balance is here negative ( -33 percent), because the proportion of the public that do not agree with the age stereotype that older people would not know enough about how to protect themselves ( 57 percent) is higher than those who agree with the age stereotype ( 24 percent) (see figure 1).

\section{RESULTS 2}

Based on previous research on age stereotypes being biased towards researching older adults and negative stereotypes $[6,10]$, and news reporting of older adults traveling on spring holidays without a care in the world, there was an expectation that the beliefs of insufficient social distancing would primarily be directed towards individuals over the age of 70 years. The results, contrary to the expectation that negative stereotypes of older adults should dominate the public opinion, rather the negative stereotype of younger people not distancing themselves enough is the most common. Nearly three-quarters of the public completely or partially agree that individuals under the age of 30 do not limit their social contacts sufficiently due to the corona virus (see figure 1). This while a sixth of the public rather dissociate themselves from the stereotype because they hardly or not at all agree with the corresponding statement. But the public also largely agrees with the corresponding age stereotype regarding insufficient social distancing among individuals over 70 years of age. The corresponding proportion that completely or partially agrees with this age stereotype of individuals who are older is closer to two thirds of the public (see figure 1). This while just over a quarter of the public distances themselves from such an age stereotype.

Figure 1. Share of the public that agree or disagree with statements of three age stereotypes (percent, percent balance) 


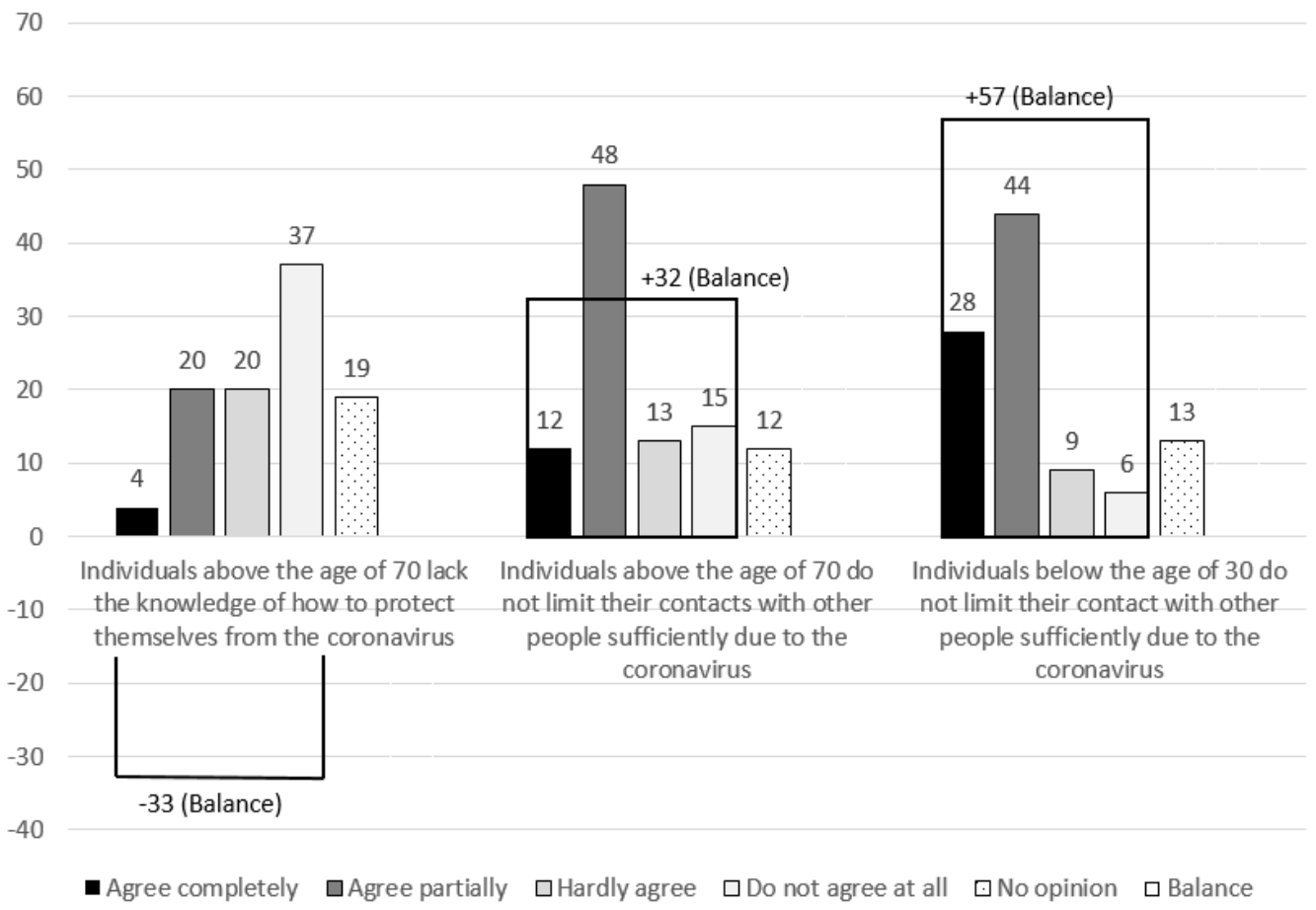

Comments: For the formulation of the question, the statements and the options to answer, please see the method section. The shares in the figure are based on all those who answered the question, and the balance measure refers to the proportion who agree that answered 'Agree completely' or 'Partially agree' minus the proportion that disagree who answered 'Hardly agree' or 'Do not agree at all'. N=2 549. Source: The national SOM survey on the coronavirus 2020.

\section{RESULTS 3}

Even though there are some cross-cultural studies on cultural differences in beliefs of age stereotypes [8,9], there is not so much is known of what characterizes the parts of the public within a specific culture, country or situation that holds beliefs of age stereotypes.

Table 1. A typology of demographical characteristics of groups that agree or disagree with statements of age stereotypes

\begin{tabular}{|c|c|c|}
\hline Statements on age stereotypes & Agree & Do not agree \\
\hline $\begin{array}{l}\text { Individuals above the age of } 70 \text { lack the } \\
\text { knowledge on how to protect themselves } \\
\text { from the corona virus. }\end{array}$ & $\begin{array}{l}\text { Is young, with a lower level of } \\
\text { education and a lower household } \\
\text { income. }\end{array}$ & $\begin{array}{l}\text { Is older, with a high level of } \\
\text { education and a high household } \\
\text { income. }\end{array}$ \\
\hline $\begin{array}{l}\text { Individuals above the age of } 70 \text { do not } \\
\text { social distance enough due to the corona } \\
\text { virus. }\end{array}$ & Is young, and a woman. & Is older, and a man. \\
\hline $\begin{array}{l}\text { Individuals under the age of } 30 \text { do not } \\
\text { social distance enough due to the corona } \\
\text { virus. }\end{array}$ & $\begin{array}{l}\text { Is young, a woman, living in an } \\
\text { urban area. Is highly educated with a } \\
\text { high household income. }\end{array}$ & $\begin{array}{l}\text { Is older, a man, living in a rural area, } \\
\text { has a lower level of education and a } \\
\text { lower household income. }\end{array}$ \\
\hline
\end{tabular}

The common demographical characteristic of the group that agree with the statements asked for in this study on age stereotypes, is that they are young, while the opposite, the group that do not agree with the statements is that they are older (see table 1). There are also differences by gender, education, residential area and level of income but they vary depending on the specific age stereotype statement in question. The public opinion on the cognitive age stereotype that individuals above the age of 70 lack the knowledge on how to protect themselves from the corona virus is gender neutral, but age and socio-economically sensitive. It is much more plausible that a persons that is young and has a lower socioeconomical level agrees with the statement of the age stereotypes than a person that is older and has a higher socioeconomical level that is more plausible to disagree with the statement (see table 1). The differences in perceptions on insufficient social distancing is age and gender sensitive. It is here more plausible that young individuals and woman hold these beliefs while individuals that are older and men do not.

\section{DISSCUSSION}

The discussion of the results is of the unexpected findings: first, that the least agreed upon age stereotype statement in the results was that individuals over the age of 70 years had poorer cognitive skills. Since this cognitive age stereotype 
according to previous research is universal, one interpretation is that this stereotype for some reason was suppressed during the corona crisis, where the primary identified risk group was older adults. Which in the light of crises communication and image repair gives you an idea of the potential power of flipping negative age stereotypes with sufficient pathos of vulnerability conveyed surrounding the stereotypically imaged primary risk group. Another interpretation is based on the result that, besides being older, the group that least agreed with this stereotype had a higher socio-economic status. Since Sweden, regarded a welfare state, have a rather high level of education and low differences in household income, this might be an explanation to why this stereotype is unusual among the public. A third interpretation is that the differences relate to the more concrete operationalization in this study, compared to previous studies of public perceptions of age stereotypes.

The second unexpected result was that the public foremost agreed with negative age stereotypes of young individuals not distancing themselves rather than older ones. A result that I mean strengthens the importance of including other age groups when analysing age stereotypes.

\section{CONCLUSION}

The main conclusion is based on the result that older adults where the group that least agreed with the negative age stereotype statements. If we assume that there is a correlation between the negative age stereotypes in the news, and the opinions of the public that are exposed to them, the result is in line with previous research on the effects of gender and ethnic stereotypes in the news on the individuals of the in-group being stereotypically portrayed. This in terms of the ingroup not being affected by the content of the negative stereotype of the group.

Research rather supports that stereotypical descriptions of a group in the news has effects on the majority group's perceptions of the stereotypically portrayed group. Translated into age stereotypes, the consequences of negative age stereotypes in the news can be that the publics' perception of older adults can be reinforced in line with the negative portrayed age stereotype. A line of reasoning supported by the results in this study that even though the negative age stereotype of young people not distancing themselves enough is the most common, still 60 percent of the public agree on that individuals above the age of 70 do not social distance enough due to the corona virus.

A challenge in risk and crisis communication is knowing when to customize the communication to different groups in order for the communication to be effective and knowing when it would work just as well following guidelines aimed at the public. To twist the results further, the use of stereotypes in the news is however a journalistic mean to get across a message quickly. But, since the group portrayed in the news do not affect the in-group portrayed, it would be fair to conclude that stereotypes are not a successful way to communicate with the group portrayed in a stereotypical way.

\section{Author Biography}

Ph.D. Gabriella Sandstig, Department of Journalism, Media and Communication, University of Gothenburg, Sweden (also current place of employment as senior lecturer). E-mail: mgabriella.sandstig@jmg.gu.se

\section{REFERENCES}

[1] https://population.un.org/wpp/ (Accessed 210119)

[2] Bennett, T., \& Gaines, J. (2010). Believing what you hear: The impact of aging stereotypes upon the old. Educational Gerontology, 36(5), 435-445. https://doi.org/10.1080/03601270903212336

[3] Robinson, T., Gustafson, B. and Popovich, M. (2008). Perceptions of negative stereotypes of older people in magazine advertisements: Comparing the perceptions of older adults and college students. Ageing and Society, 28, 233-251. https://doi.org/10.1017/S0144686X07006605

[4] Sargeant, M. (2008). Age stereotypes and the media. Tolley's communication law, 4, 120-125. (Accessed 200309)

[5] Pinquart, M. (2002). Good News About the Effects of Bad Old-Age Stereotypes, Experimental Aging Research, 28(3), 317-336, https://doi.org/10.1080/03610730290080353

[6] Hummert, M.L. (1993). Age and typicality judgements of stereotypes of the elderly: Perceptions of elderly vs. young adults. International Journal of Aging and Human Development, 37, $217-226$. https://doi.org/10.2190/L01P-V960-8P17-PL56

[7] Williams, A., \& Giles, H. (1998). Communication of ageism. In M. L. Hecht (Ed.), Communicating prejudi, 136-160. Sage Publications, Inc. https://doi.org/10.4135/9781483328263.n8

[8] Cuddy, A. C., Norton, M. I. and Fiske, S. T. (2005). This old stereotype: the pervasiveness and persistence of the elderly stereotype. Journal of Social Issues, 61, 267-285. https://doi.org/10.1111/j.1540-4560.2005.00405.X

[9] Yun, R. J. and Lachman, M. E. (2006). Perceptions of aging in two cultures: Korean and American views on old age. Journal of Cross-cultural Gerontology, 21, 55-70. https://doi.org/10.1007/s10823-006-9018-y

[10] Levy, B. (2003). Mind matters: cognitive and physical effects of aging self stereotypes. Journal of Gerontology: Psychological Sciences, 58B(4), 203-211. https://doi.org/10.1093/geronb/58.4.P203 